\title{
INFLUENCE OF COLLECTION TIME ON THE DETERMINATION OF ROOT EXUDATES IN FRAXINUS MANDSHURICA BY THE METABOLOMICS METHOD
}

\author{
LI, L. Y. ${ }^{1,2}-$ FENG, C. X. ${ }^{1}-$ ZHANG, Y. D. ${ }^{1 *}$ \\ ${ }^{1}$ College of Forestry, Northeast Forestry University \\ Harbin 150040, Heilongjiang, People's Republic of China \\ ${ }^{2}$ Heilongjiang BaYi Agricultural University \\ Daqing 163319, Heilongjiang, People's Republic of China \\ *Corresponding author \\ e-mail:zhyd63@163.com
}

(Received 18 ${ }^{\text {th }}$ Apr 2019; accepted $10^{\text {th }}$ Jun 2019)

\begin{abstract}
Root exudates play an important role in the control of soil ecology because they are major sources of organic carbon and energy for plants, and they drive the carbon cycle of forest ecosystems. However, qualitative and quantitative methods for analysis of root exudates are poorly developed. In this study, Fraxinus mandshurica was used as research material for studying the influence of different collection times on the chemical composition of root exudate. The study employed qualitative and metabolomic analyses of root exudates with gas chromatography-mass spectrometry, and quantitatively analyzed root exudates of F. mandshurica with ultrahigh performance liquid chromatography (UPLC) and high performance ion chromatography (HPIC) methods. Root exudates were collected after harvest for $24 \mathrm{~h}$ at $6 \mathrm{~h}$-intervals, and then analyzed. The types of sugars, amino acids, and organic acids in the root exudates were not significantly different among the four exudate samples. The results indicated that collection time strongly influenced the level of organic compounds in root exudates from $F$. mandshurica, with an optimal collection time of $12 \mathrm{~h}$. In addition, quantitative analysis of root exudates using UPLC and HPIC had greater advantage, when compared with conventional analytical methods.
\end{abstract}

Keywords: Fraxinus mandshurica, exudate, qualitative analysis, quantitative analysis, GC-MS, UPLC, HPIC

\section{Introduction}

Root exudates refer to organic compounds actively or passively released from plant roots to the surrounding rhizosphere under specific conditions. Exudates include some low molecular weight compounds such as organic acids, sugars, phenols, and amino acids (Malandrino et al., 2011). Some high molecular weight organic compounds such as proteins and mucus are also present in exudates (Dijkstra and Cheng, 2007). Studies have shown that root exudates influence soil material cycling by changing the physical and chemical properties of soil (Materechera et al., 1992; Oades, 2010). Root exudates are affected by plant nutrient uptake (Li et al., 2007; Dinkelaker et al., 2010). They are involved plant signal transduction (Peters et al., 1986; Akiyama et al., 2005), and they interact with rhizospheric microorganisms (Bardgett et al., 2005; Singh and Mukerji, 2006). Root exudates significantly change the abundance and activity of soil microorganisms, thereby profoundly affecting organic matter decomposition and nutrient metabolism in the rhizosphere (Phillips et al., 2009; Yin et al., 2013). Root exudates play important roles in the regulation of soil nutrient transformation. These 
findings were based on analysis of the composition of root exudates. Thus, analysis of composition of root exudates is of great significance.

Research related to identification of the compositions of root exudates have focused mainly on sugars, amino acids and organic acids (Kuo et al., 1982; Zhen et al., 2004; Sandnes et al., 2005; Kerdchoechuen, 2005; Chang et al., 2008; García et al., 2010; Carvalhais et al., 2011). Thus, there is dearth of information on other components of exudates. There is need for a comprehensive analysis of the composition and trends of root exudates because they vary in types and amounts under different treatment conditions. In addition, many factors influence the composition of root exudates. These include forest type, tree species, environmental conditions, and soil nutrient availability (Zhang et al., 2007; Fransson and Johansson, 2010; Shi et al., 2011). Water culture collection method has been widely used for the collection of root exudates because it is simple to implement, and it reflects changes in certain root secretions to a certain extent, while eliminating interference from soil microorganisms (Phillips et al., 2006). However, the influence of collection time on water culture collection method for the analysis of root exudates has not been investigated. Recent studies have employed collection times of 6, 12, 18, and $24 \mathrm{~h}$ (Li et al., 2014; Liu et al., 2016). The compositions of root exudates have also been shown to change as a function of collection time (Bowsher et al., 2015). This is so because plants and the environment change over time in ways that affect the results of compositional analysis of root exudates. However, no studies have so far been carried out on the trends of changes in compositions of root exudates over time. Currently, studies on root exudates have concentrated mostly on qualitative analysis, with only few reports on quantitative studies. Qualitative analysis usually involves the use of various solvents to extract root exudates, and carrying out analysis using gas chromatography (GC) or gas chromatography-mass spectrometer (GC-MS). However, these methods may seriously affect the accuracy of the analysis. Quantitative analysis often involves the use of amino acid analyzer (for amino acids), high performance liquid chromatography (for organic acids), and anthrone reagent and phenol-sulfuric acid colorimetric assays (for sugars) (Xiao et al., 2015; Zhang et al., 2016; Wang et al., 2016). The accuracy and limits of detection of these methods are poor, and they lack specificity. Thus, the quantitative results are not reliable and credible. In recent years, GC-MS, ultra-performance liquid chromatography (UPLC), high performance ion chromatography (HPIC), metabolomics, and other related hi-tech methods have been widely used. These methods have the advantages of high accuracy and precision, and low detection limits, and they provide rapid analysis within relatively wide linear ranges (Rissanen et al., 2006; Kajos et al., 2015; Dietrich et al., 2016; Gargallogarriga et al., 2017). However, few studies and applications exist based on these methods for the analysis of root exudates. Therefore, it is necessary to use these methods for the analysis of root exudates.

Previous studies related to root exudates have mainly concentrated on short-growingperiod plants such as crops and vegetables (Venkatasubbarao and NoriharuAe, 1997; Paynel et al., 2001; Luo et al., 2014), while similar studies on perennial forest species are rare. Fraxinus mandshurica ( $F$. mandshurica), an important afforestation tree species with high ecological and economic value in Northeast China, has roots with welldeveloped branching structure (Mei et al., 2006; Ren et al., 2010). It is suitable for the study of root biology, especially in the determination and analysis of root exudates, and it has a certain level of practical significance. Therefore, in this study, the root exudates of $F$. mandshurica in the cold forests of northeastern China were qualitatively analyzed 
using GC-MS technology, and the metabolomic differences at different collection times were determined. Based on qualitative analysis, the amino acids and organic acids were analyzed using targeted UPLC method, while the sugars were analyzed with targeted HPIC method. The trend of changes in the composition and contents of components of root exudates of $F$. mandshurica at different collection times were analyzed to determine the best collection time. The goal of the present study was to establish efficient qualitative and quantitative methods for analyzing root exudates, and to provide a theoretical reference for this process.

\section{Materials and Methods}

\section{Plant materials and culture methods}

One-year-old $F$. mandshurica saplings with uniform size and robustness were selected to ensure as much consistency as possible between individual saplings. These saplings were grown in the nursery of Forestry and Environmental Sciences, Northeast Forestry University of China. The saplings were pre-cultured for 7 days using deionized water, and then cultured using a nutrient solution. The nutrient solution was replaced every 3 days during culture. The $\mathrm{pH}$ of the nutrient solution was adjusted to 5.5 with 0.1 $\mathrm{M} \mathrm{NaOH}$ or $0.1 \mathrm{M} \mathrm{HCl}$, and $24 \mathrm{~h}$ ventilation was maintained constantly. After 15 days of continuous culture, the root exudates were collected. At that time, the $F$. mandshurica saplings had vigorous root growth.

\section{Collection of roof exudates}

Prior to analysis, the roots of each $F$. mandshurica sapling were removed from the nutrient solution, washed 3-5 times with deionized water, and placed inside a $100-\mathrm{mL}$ beaker which was shaded with black rubberized fabric. Then, the root exudates were collected after $6,12,18$, and 24 h. Finally, the root exudates were dried using a vacuum freeze-drying machine (Shanghai Yuming Instrument Co., Ltd., Shanghai, China). At least, six replicate samples were used for each group of experiments.

\section{The GC-MS analysis preprocessing methods}

Next, qualitative and metabolite analyses of the root exudates were carried out using GC-MS analysis in accordance with the method of Suzuki et al. (2009), with a slight modification. First, freeze-dried root exudates were added to a cold methanol: water $=$ 4:1 solution $(1 \mathrm{~mL})$. This was blown to dryness with nitrogen. Then, $20 \mu \mathrm{L}$ of internal standard (L-2-chlorobenzene alanine, $0.3 \mathrm{mg} / \mathrm{mL}$, configuration of methanol) was added. This was then mixed with $600 \mu \mathrm{L}$ methanol-acetonitrile (2:1) and stirred for $30 \mathrm{sec}$. The root exudates were extracted after $10 \mathrm{~min}$ in an ice water bath with an ultrasonic cleaning machine (Ji Ning SIONBEST Biology Machinery Co., Ltd., Shandong, China). Next, samples were centrifuged for $15 \mathrm{~min}$ at $13000 \mathrm{rpm}$ and at temperature of $4^{\circ} \mathrm{C}$. Then, $500 \mu \mathrm{L}$ supernatant was loaded into a glass derivative bottle, and the samples were dried with a centrifuge drying apparatus (Labconco Corporation, Kansas, Missouri, USA). Thereafter, $80 \mu \mathrm{L}$ of $15 \mathrm{~g} / \mathrm{L}$ methoxyamine hydrochloride pyridine was added and allowed to react for $90 \mathrm{~min}$, with oscillation of the reaction mixture at $37^{\circ} \mathrm{C}$. Next, 80 $\mu \mathrm{L}$ bis(trimethylsilyl)trifluoroacetamide (1\% trimethylchlorosilane) was added and allowed to react with the oxime reaction for $60 \mathrm{~min}$ at $70^{\circ} \mathrm{C}$, accompanied with 
oscillation (Young et al., 2010). Finally, the samples were filtered into GC sample bottles using a filter membrane (Pall Corporation., New York, USA) $(0.45 \mu \mathrm{m})$, and used in the metabolomic analysis with GC-MS.

\section{Chromatographic conditions for GC-MS analysis}

A GC-MS analyzer 7890A-5975C (Agilent, Santa Clara, CA, USA) and an HP-5MS capillary chromatographic column $(30 \mathrm{~m} \times 0.25 \mathrm{~mm} \times 0.25 \mu \mathrm{m}$, Agilent J\&W Scientific, Folsom, CA, USA) were used for GC analysis. The initial temperature of the chromatographic column was $60^{\circ} \mathrm{C}$, and it was ramped up to $310^{\circ} \mathrm{C}$ at the rate of $8^{\circ} \mathrm{C} / \mathrm{min}$, and held for $6 \mathrm{~min}$. Sample volume was $1 \mu \mathrm{L}$, inlet temperature was $260^{\circ} \mathrm{C}$, and high purity helium was used as carrier gas at a flow rate of $1.0 \mathrm{~mL} / \mathrm{min}$. Electric impact was used as ion (EI) and the ion source temperature was $230^{\circ} \mathrm{C}$. Quadrupole temperature was $150^{\circ} \mathrm{C}$, and the electron energy was $70 \mathrm{eV}$. The scanning square was full scan mode (SCAN), and the quality scanning range was $50-600 \mathrm{~m} / \mathrm{z}$. Continuous sample analysis was carried out in random order to avoid the influence caused by fluctuation in the instrument signal.

\section{Metabolite identification and integration of data matrix}

The original data of GC/MS (D format) was converted to general format (CDF format) through Chem Station analysis software (Version E.02.02.1431, Agilent, USA), and the data pre-processing used Chroma TOF software (Version 4.34, LECO, St Joseph, MI, USA). It included peak extraction, noise elimination and deconvolution, and used the standards of the US National Institute of Standards and Technology and the Fiehn database to identify metabolites. Finally, peak alignment was performed, and 3D data matrix (original data matrix) in CSV format was derived.

\section{Methods used for metabolite data analysis}

The metabolite content was used as $\mathrm{X}$ variable. Then, a matrix was established and imported into SIMCA-P 14.1 (Umea, Sweden) software for multivariate statistical analysis. The clustering was analyzed using PCA (principal component analysis, PCA). Then, a reliable statistical analysis model was established using partial least-squares discriminant analysis (PLS-DA) which searched for significant differences between samples taken at different time points, and identified which biomarkers were useful for classification. The reliability of the model was evaluated using the explanatory power of model to variables (R2) and predictive ability (Q2), while the fit of the model was assessed using overfitting evaluation index R2- and Q2-intercepts. Significant differences between metabolites was determined using loading plot of PLS-DA and the Variable Importance for the Projection (VIP). The biomarker was VIP $>1$.

\section{Analysis of amino acid content}

The amino acid content was analyzed with UPLC. The amino acids were derivatized using o-phthaldialdehyde and fluorenylmethyl chloroformate, and qualitative analysis was carried out through the retention times of chromatographic peaks, while quantitative analysis was done using external standard method. Freeze-dried root exudates were used for analysis of amino acid targets, with addition of deionized water $(1 \mathrm{~mL})$ under 
ultrasonic conditions. After centrifugation for $10 \mathrm{~min}$ at $12000 \mathrm{rpm}$, it was filtered through a $20 \mu \mathrm{m}$ filter membrane.

\section{Preparation amino acid standard samples}

Amino acid standard $(1 \mathrm{~mL}, 1000 \mathrm{pmol} / \mu \mathrm{L})$ was divided into ten parts $(100 \mu \mathrm{L})$. The standard contained aspartic acid (Asp), glutamic acid (Glu), asparagine (Asn), serine (Ser), glutamine (Gln), histidine (His), glycine (Gly), threonine (Thr), arginine (Arg), alanine (Ala), tyrosine (Tyr), valine (Val), methionine (Met), tryptophan (Trp), phenylalanine (Phe), isoleucine (Ile), leucine (Leu), lysine (Lys), and proline (Pro). Amino acid supplement solution I was prepared by weighing Asn (237.8 mg), hydroxyproline $(236 \mathrm{mg})$, Glu $(263.08 \mathrm{mg})$ and $\operatorname{Trp}(367.8 \mathrm{mg})$ into a measuring flask $(100 \mathrm{~mL})$, and adding $0.1 \mathrm{M}$ hydrochloric acid $(50 \mathrm{~mL})$. The amino acids were dissolved under ultrasonic conditions, and then diluted to scale with deionized water. Amino acid supplement solution II was prepared by dissolving norvaline $(234.32 \mathrm{mg})$ in $100 \mathrm{~mL}$ of $0.1 \mathrm{M} \mathrm{HCL}$ in a $200 \mathrm{~mL}$ measuring flask, under ultrasonic conditions and then diluting to scale with deionized water. This solution was used as an internal standard solution. The mixed standard solution was prepared by mixing amino acid supplement solutions I and II (10 $\mu \mathrm{L}$ of each). The mixture was vortexed using a vortex vibration instrument (Shanghai Jingke Industrial Co., Ltd., Shanghai, China). The mixed standard solution was diluted to 1:1000, 5:1000, 10:1000, 100:1000, 200:1000, 500:1000, and 1000:1000 to generate gradient concentrations of each amino acid standard i.e. $1 \mathrm{nmol} / \mathrm{mL}, 5$ $\mathrm{nmol} / \mathrm{mL}, 10 \mathrm{nmol} / \mathrm{mL}, 100 \mathrm{nmol} / \mathrm{mL}, 200 \mathrm{nmol} / \mathrm{mL}, 500 \mathrm{nmol} / \mathrm{mL}$, and $1000 \mathrm{nmol} / \mathrm{mL}$, respectively.

\section{UPLC detection method}

Model U3000 DGLC UPLC analyzer (Thermo Fisher Scientific, Waltham, MA, USA) and Advance Bio AAA C18 chromatographic column $(4.6 \times 100 \mathrm{~mm}, 2.7 \mu \mathrm{m}$, Agilent J\&W Scientific, Folsom, CA, USA) were used for amino acid analysis. The automatic sampler program involved valve switch to bypass $6 \mathrm{sec}$ after sample injection. The sample $(1.0 \mu \mathrm{L})$ and borate buffer $(2.5 \mu \mathrm{L})$ were mixed five times at the cleaning mouth $(3.5 \mu \mathrm{L})$, and after $12 \mathrm{sec}$, o-phthaldialdehyde $(0.5 \mu \mathrm{L})$ was added, and mixed ten times at cleaning mouth $(4.0 \mu \mathrm{L})$. Next, fluorenylmethyl chloroformate $(0.4 \mu \mathrm{L})$ was added and mixed ten times at cleaning mouth $(4.4 \mu \mathrm{L})$, followed with addition of doubledistilled water $\left(\mathrm{ddH}_{2} \mathrm{O}\right)(15.6 \mu \mathrm{L})$ and mixing eight times at cleaning mouth $(20 \mu \mathrm{L})$. Finally, the sample was injected into the chromatographic column. The chromatographic conditions were: column temperature of $40^{\circ} \mathrm{C}$ and flow rate of $1.5 \mathrm{ml} / \mathrm{min}$. Mobile phase A was $10 \mathrm{mM}$ sodium hydrogen phosphate and $10 \mathrm{mM}$ sodium borate solution, with $\mathrm{pH}$ adjusted to 8.2 with hydrochloric acid. Mobile phase B was methanol: acetonitrile: water at volume ratio of 45: 45: 10 . The gradient program used was $2 \% \mathrm{~B}$ for $0-13.4 \mathrm{~min}, 57 \%$ B for 13.4-13.5 min, 100\% B for 13.5-15.7 min, and 2\% B for 15.7-18.0 min. The study was carried out at $338 \mathrm{~nm}$ (bandwidth $10 \mathrm{~nm}$, reference $390 \mathrm{~nm}$, bandwidth $20 \mathrm{~nm}$, first class amino acids); and $262 \mathrm{~nm}$ (bandwidth $16 \mathrm{~nm}$; reference $324 \mathrm{~nm}$, bandwidth $8 \mathrm{~nm}$, level two amino acids). The wavelength was switched after lysine peaks (the experiment was set to switch from $338 \mathrm{~nm}$ to $262 \mathrm{~nm}$ in $10 \mathrm{~min}$ ). Chameleon software ver. 7.2 (Thermo Fisher Scientific, Leipzig, Germany) was used for data analysis and final data collation. 


\section{Target analysis method for sugars}

Sugars were analyzed using HPIC. First, the sugars were separated in an anion exchange column and detected with a pulse integral amperometric detector (Thermo Fisher). The retention time of chromatographic peaks were determined, and quantitative analysis were carried out using the external standard method. Freeze-dried root exudates were used for sugar target analysis, which involved adding deionized water $(1 \mathrm{~mL})$ under ultrasonic conditions, centrifugation for $10 \mathrm{~min}$ at $12,000 \mathrm{rpm}$, and filtration through a $20-\mu \mathrm{m}$ filter membrane.

\section{Preparation of standard sugar solutions}

First, $100 \mathrm{mg}$ of each sugar was dissolved in $10 \mathrm{~mL}$ of deionized water, and the solution was diluted 100 times. The sugar standards used were fucose (fuc), arabinose (ara), galactose (gal), glucose (glc), xylose (xyl), mannose (man), fructose (fru), ribose (rib), galacturonic acid (gal-AC), and glucuronic acid (glc-AC). The concentration of the standard solution was $100 \mu \mathrm{g} / \mathrm{mL}$. Each mixed standard solution was diluted at ratios of $1: 100,5: 100,10: 100,20: 100,30: 100,40: 100,50: 100$, and $60: 100$, so that the concentration of each sugar standard after dilution was $1 \mu \mathrm{g} / \mathrm{mL}, 5 \mu \mathrm{g} / \mathrm{mL}, 10 \mu \mathrm{g} / \mathrm{mL}$, $20 \mu \mathrm{g} / \mathrm{mL}, 30 \mu \mathrm{g} / \mathrm{mL}, 40 \mu \mathrm{g} / \mathrm{mL}$, and $60 \mu \mathrm{g} / \mathrm{mL}$, respectively.

\section{HPIC detection method}

An ICS5000 HPIC analyzer (Thermo Fisher) and Dionex ${ }^{\text {TM }}$ CarboPac ${ }^{\mathrm{TM}}$ PA20 $(3.0 \times 150 \mathrm{~mm}$, Thermo Fisher) were used for the analysis of sugars, along with an electrochemical detector at a flow rate of $0.5 \mathrm{ml} / \mathrm{min}$. Mobile phase A was double distilled $\mathrm{ddH}_{2} \mathrm{O}$, while mobile phase $\mathrm{B}$ was $200 \mathrm{mM} \mathrm{NaOH}$, and mobile phase $\mathrm{C}$ was $200 \mathrm{mM}$ $\mathrm{NaOH}: 500 \mathrm{mM} \mathrm{NaAC}$. The gradient program was $97.5 \% \mathrm{~A}+2.5 \% \mathrm{~B}$ for $0-25 \mathrm{~min}$; $77.5 \% \mathrm{~A}+2.5 \% \mathrm{~B}+20 \% \mathrm{C}$ for $25.0-40 \mathrm{~min} ; 100 \% \mathrm{C}$ for $40.0-50 \mathrm{~min}$; and $97.5 \% \mathrm{~A}+$ $2.5 \% \mathrm{~B}$ for $50.0-60 \mathrm{~min}$. Chameleon software (7.2) was used for data analysis and final data collation.

\section{Organic acid analysis method}

Organic acid contents were determined using HPIC. The organic acids were separated with AS11 HC. Qualitative analysis was done by measuring the retention time of chromatographic peaks, while quantitative analysis was done using external standard method. Freeze-dried root exudates were used for organic acid target analysis after addition of deionized water $(1 \mathrm{~mL})$ under ultrasonic conditions, centrifugation for $10 \mathrm{~min}$ at $12,000 \mathrm{rpm}$, and filtration through a $20-\mu \mathrm{m}$ filter membrane.

\section{Preparation of standard solutions of organic acids}

Standard solutions were prepared for lactic, acetic, propionic, formic, isobutyric, butyrate, isovalerate, valerate, isohexadecanoic, hexadecanoic, palmitic, succinic, tartaric, and oxalic acids by dissolving $100 \mathrm{mg}$ of each organic acid in $10 \mathrm{~mL}$ of deionized water and diluting the resultant solution 100 times. The concentration of each standard solution was $100 \mu \mathrm{g} / \mathrm{mL}$. Serial dilutions of each standard solution were prepared at ratios of $1: 100,5: 100,10: 100,20 ; 100,30 ; 100,40 ; 100,50 ; 100$, and $60 ; 00$ to yield organic acid standard concentrations of $1 \mu \mathrm{g} / \mathrm{mL}, 5 \mu \mathrm{g} / \mathrm{mL}, 10 \mu \mathrm{g} / \mathrm{mL}, 20 \mu \mathrm{g} / \mathrm{mL}, 30 \mu \mathrm{g} / \mathrm{mL}, 40 \mu \mathrm{g} / \mathrm{mL}$, and $60 \mu \mathrm{g} / \mathrm{mL}$, respectively. 


\section{HPIC detection method}

An ICS5000 HPIC analyzer (Thermo Fisher), an AS11 HC Dionex ${ }^{\mathrm{TM}}(4.0 \times 250 \mathrm{~mm}$, Thermo Fisher), and an AS11 HC Guard $(4.0 \times 50 \mathrm{~mm}$, Thermo Fisher) were used for organic acid analysis with an electrochemical detector, flow rate of $1.0 \mathrm{ml} / \mathrm{min}$, and column temperature of $30^{\circ} \mathrm{C}$. Mobile phase A was $\mathrm{ddH}_{2} \mathrm{O}$ (18.2M $\Omega$ Pall, USA), while mobile phase B was $100 \mathrm{mM} \mathrm{KOH} \mathrm{(HPLC,} \mathrm{Sigma,} \mathrm{USA).} \mathrm{The} \mathrm{gradient} \mathrm{elution} \mathrm{program}$ was $2.0 \%$ B for $0-15 \mathrm{~min}$; $15 \%$ B for $15-30 \mathrm{~min}$; $40 \%$ B for $30-40 \mathrm{~min}$; $50 \%$ B for $40-45$ $\mathrm{min}$; and 2.0\% B for 45-53 min. Chameleon software (7.2) was used for data analysis and collation of final data.

\section{Statistical analysis}

Data are presented as mean \pm standard deviation $(n=6)$. Statistical analyses were performed with SAS statistical program. Statistical significance of differences amongst the groups were analyzed with one-way analysis of variance (ANOVA), followed by Duncan's test. Statistical significance was assumed at $p<0.05$.

\section{Results and Discussion}

\section{Results of root exudate metabolite analysis using GC-MS}

The qualitative analysis of the root exudates of $F$. mandshurica was carried out using GC-MS. Two hundred and nineteen compounds were found in the root exudates of $F$. mandshurica. The root exudates contained lactic, acetic, oxalic, tartaric, succinic, and other small molecular organic acids such as aspartic acid, asparagine, glycine, alanine, valine, isoleucine, and leucine, amongst others. The other compounds included amino acids, xylose, fructose, glucose and other sugars. Erythronolactone, hydroxylamine, monostearin, nicotinic acid, ribitol, methylhydantoin, phytosphingosine, linoleic acid, hexadecane, sedoheptulose, and other small molecular metabolites were also present. The result agrees with those obtained in previous studies which reported the presence of many compounds in the root exudate (Luo et al., 2014; Han et al., 2015). Luo found 62 compounds in Sedum alfredi, including organic acids, amino acids, sugars and other small molecular metabolites. Over 100 compounds were identified in Capsicum chinense Jacquin, including organic acids, amino acids, sugars and other small molecular weight metabolites (alkane, lipids, acids, alcohols, phenols, aldehydes, oxime, pyrrolidone, amide, amine and naphthalene compounds) (Han et al., 2015). The type of compound present in plant exudates is determined by factors such as species of plant, period of growth, nutrient level and environmental pressure (Carvalhais et al., 2011; Selvakumar and Panneerselvam, 2012). The present study also found that the compounds in root exudates of $F$. mandshurica varied at different collection times. Therefore, a metabolomics analysis was carried out on the original data of GC/MS (CDF format), so as to identify the differences in levels of metabolites of root exudates of $\mathrm{F}$. mandshurica as a function of time of collection. Plots of PCA scores (Fig. 1-a) showed that samples at different collection times had a preliminary clustering trend, meaning that metabolites in samples collected at different times were different. In addition, quality control samples were clustered and distributed in the score map, indicating an improvement in the stability of the detection platform. The results of the PLS-DA score plots (Fig. 1-b) showed that the samples collected at different times were completely clustered and separated, and 
sample distribution for samples collected from $6 \mathrm{~h}$ to $24 \mathrm{~h}$ showed a gradual and progressive relationship.

Through model verification analysis (Fig. 2), this study found that the interpretations of the model for $\mathrm{X}$ and $\mathrm{Y}$ variables were $R^{2} \mathrm{X}=0.441$ and $R^{2} \mathrm{Y}=0.907$, respectively, and the prediction of the variable $Q^{2} Y$ was 0.622 , which showed that the model was of good quality. After 999 permutation tests, $R^{2}$-interposition was $0.593, Q^{2}$-interposition was -0.450 , and all random permutations produced $R^{2} Y$ and $Q^{2}$ values smaller than the original $R^{2} \mathrm{Y}, Q^{2}$ values, indicating that the PLS-DA model was robust.
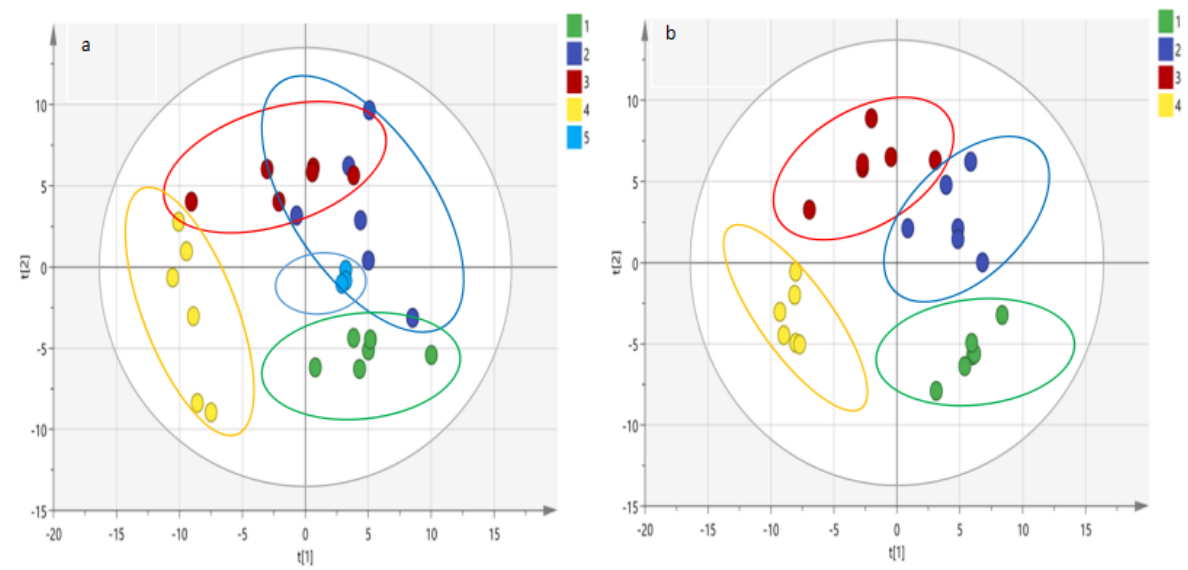

Figure 1. (a) Principal component analysis (PCA) and (b) partial least-squares discriminant analysis (PLS-DA) score plots of root exudates of the $F$. mandshurica. Collection times were at (1) $6 \mathrm{~h}$, (2) $12 \mathrm{~h}$, (3) $18 \mathrm{~h}$ and (4) $24 \mathrm{~h}$. (5): quality control sample

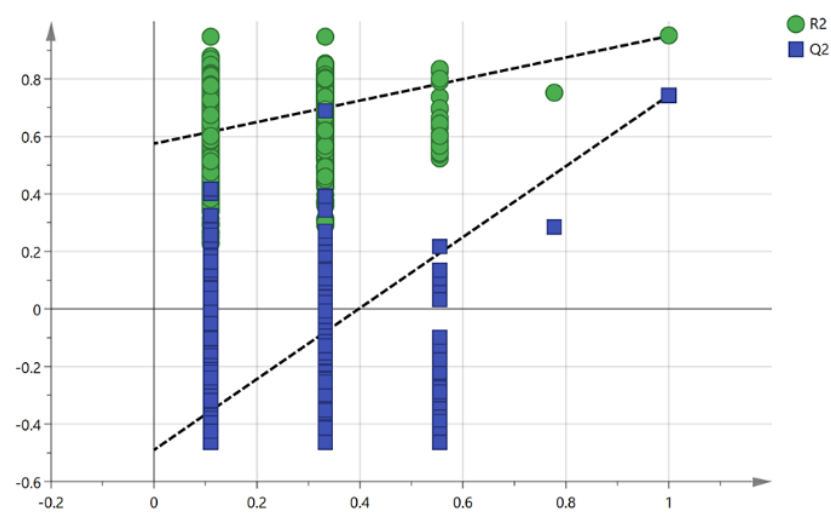

Figure 2. Verification analysis of partial least-squares discriminant analysis model. The explanatory of models $R^{2}$ and the predicted performances of models $Q^{2}$ were 0.593 and 0.450 respectively. Overfitting of the model was discriminated using $R^{2}$-intercepts and $Q^{2}$-intercepts

Results of the loading plot of the PLS-DA model (Fig. 3) showed that the samples from different collection times differed significantly, and the differential metabolites were identified using VIP analysis. These included glycolic acid, acetophenone, glucose1-phosphate, 15-keto-prostaglandin, dithioerythritol, dehydroabietic acid, thioctamide, synephrine, hippuric acid, quinic acid, sedoheptulose, nicotinamide, 2-hydroxybiphenyl, 2-deoxyuridine, 2-furoic acid, maleamate, 6-hydroxy caproic acid trimer, beta- 
hydroxypyruvate, halostachine, and other metabolites, totaling 88 compounds (VIP>1). The results showed that the secondary metabolites accounted for a larger proportion of the metabolites that differed significantly at different collection times, while the sugars, amino acids, and small molecular organic acids were not significantly different amongst root exudates of $F$. mandshurica collected at different times. The results are in agreement with the findings of previous studies, which were mainly focused on sugars, amino acids, and organic acids (Huang et al., 1996; Maqsood et al., 2011; Carvalhais et al., 2011). Therefore, the present study quantitatively analyzed the sugar, amino acid, and organic acid compounds in the root exudate of $F$. mandshurica, and investigated how these compounds varied at different collection times. This was with a view to determining the optimal collection time of the root exudate.

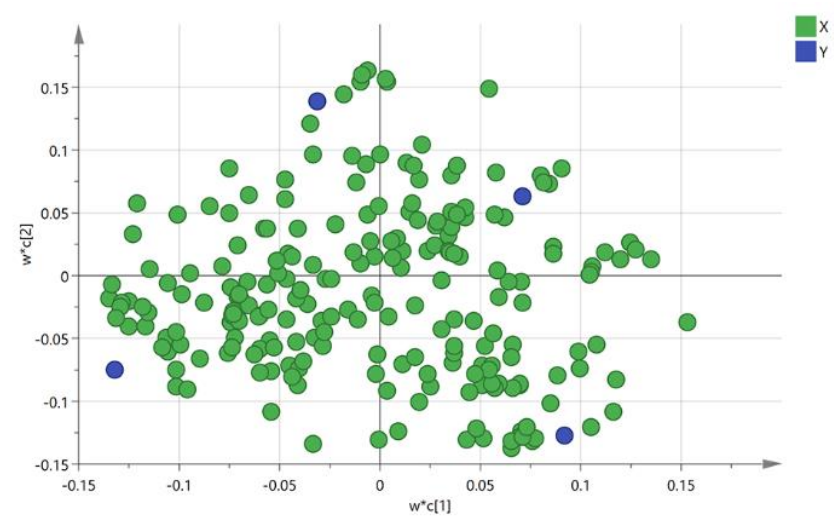

Figure 3. Loading plot of partial least-squares discriminant analysis model for root exudates of F. mandshurica: $(X)$ root exudate variable, $(Y)$ group (collection time) variable

\section{Results of amino acid analysis of root exudates using UPLC}

Qualitative analysis was done using the retention time of chromatographic peaks (Fig. 4), while quantitative analysis was carried out using the external standard method. Results of amino acid analysis of root exudates from $F$. mandshurica (Table 1) showed that the primary amino acids were Asp, Asn, Gly, Ala, Val, Ile, and Leu. There was a wide variation in amino acids between the results obtained from UPLC analysis and results from GC-MS analysis. There were fewer amino acids in UPLC analysis results than in GC-MS analysis results. This variation was probably due to the fact that the detection limit of GC-MS is lower than that of UPLC. Thus, when the amino acid content is low, it may be below the lower limit for UPLC detection, resulting in inability of the UPLC method to detect some amino acids. It was also found that the varieties and the contents of amino acids varied significantly at different collection times. The amount and varieties of amino acids found initially showed significantly increasing trend as the collection time increased ( $0-12 \mathrm{~h}$ ), but decreased significantly after $12 \mathrm{~h}$. Indeed, only Gly was present in the root exudates at $18 \mathrm{~h}$ and $24 \mathrm{~h}$. This occurred because the amino acids from root exudates were used as nitrogen substrates by $F$. mandshurica. Thus, with continuous use, the amino acids were close to depletion at 18-24 h. Therefore, the best time to collect the root exudates for the determination of amino acid content is $12 \mathrm{~h}$. The content of Gly was the highest among the various amino acids of root exudates. The contents of Leu, Val, and Ile were also high. However, the contents of Ala, Asp, and Asn 
were the lowest at $12 \mathrm{~h}$, based on analysis of variance. Therefore, in the present study, UPLC had a lower detection limit for amino acids, relative to previous studies that used amino acid analyzer (Dong et al., 2015; Pan et al., 2016). Thus, the UPLC method employed here can be used for the determination of low levels of amino acids in root exudates.

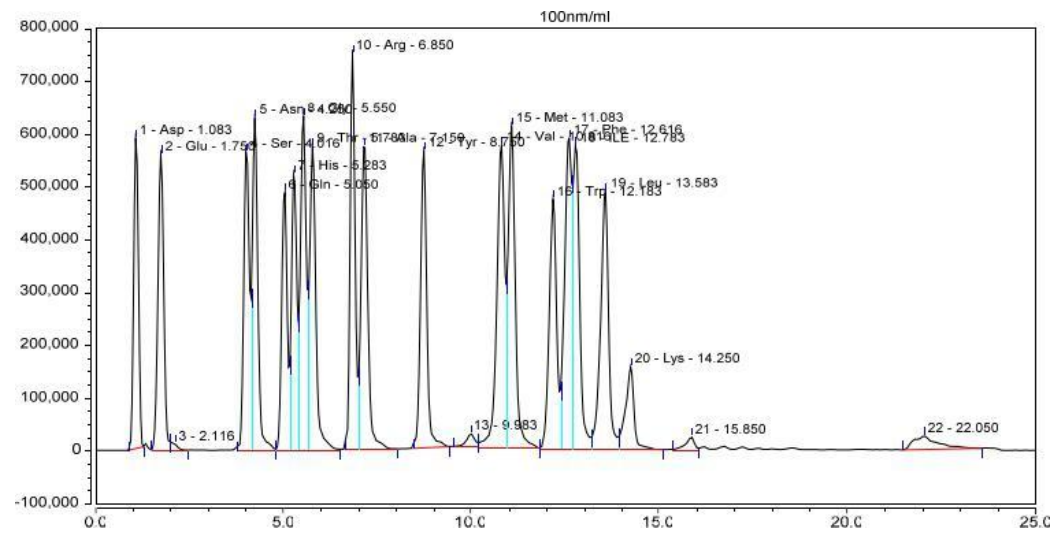

Figure 4. Ultra-high performance liquid chromatography (UPLC) chromatogram of amino acid standards at concentration of $100 \mathrm{nmol} / \mathrm{mL}$. Retention times of amino acids for: peak 1, arginine (Arg), 1.083 min; peak 2, glutamic acid (Glu), 1.750 min; peak 4, serine (Ser), 4.016 min; peak 5, asparagine (Asn), 4.250 min; peak 6, glutamine (Gln), 5.050 min; peak 7, histidine (His), 5.283 min; peak 8, glycine (Gly, 5.550 min; peak 9, threonine (Thr), 5.783 min; peak 10, argnine (Arg), 6.850 min; peak 11, alanine (Ala), 7.150 min; peak 12, tyrosine (Tyr), 8.750 min; peak 14, valine (Val), 10.816 min; peak 15, methionine (Met), 11.083 min; peak 16, tryptophan (Trp), 12.183 min; peak 17, phenylalanine (Phe), 12.616 min; peak 18, isoleucine (Ile), 12.783 min; peak 19, leucine (Leu), 13.583 min; peak 20, lysine (Lys), 14.250 min. Peaks 3, 13, 21, and 22 were solvent peaks

Table 1. Amino acid contents of root exudates of $F$. mandshurica as determined using UPLC. (There were 4 treatments based on collection times of $6 \mathrm{~h}, 12 \mathrm{~h}, 18 \mathrm{~h}$ and $24 \mathrm{~h}$ )

\begin{tabular}{c|c|c|c|c|c|c|c}
\hline \multirow{2}{*}{$\begin{array}{c}\text { Time of } \\
\text { collection }\end{array}$} & \multicolumn{7}{|c}{ Amino acid content $(\mathrm{nmol} / \mathrm{mL})$} \\
\cline { 2 - 8 } & Asp & Asn & Gly & Ala & Val & Ile & Leu \\
\hline $6 \mathrm{~h}$ & n.a. & $0.66 \pm 0.08^{\mathrm{a}, \mathrm{D}}$ & $7.02 \pm 0.15^{\mathrm{b}, \mathrm{A}}$ & n.a. & $1.07 \pm 0.07^{\mathrm{b}, \mathrm{C}}$ & n.a. & $3.51 \pm 0.21^{\mathrm{b}, \mathrm{B}}$ \\
$12 \mathrm{~h}$ & $1.30 \pm 0.04^{\mathrm{F}}$ & $0.22 \pm 0.03^{\mathrm{b}, \mathrm{G}}$ & $20.66 \pm 0.51^{\mathrm{a}, \mathrm{A}}$ & $3.05 \pm 0.11^{\mathrm{E}}$ & $7.93 \pm 0.26^{\mathrm{a}, \mathrm{B}, \mathrm{C}}$ & $7.39 \pm 0.17^{\mathrm{D}}$ & $8.15 \pm 0.44^{\mathrm{a}, \mathrm{B}}$ \\
$18 \mathrm{~h}$ & n.a. & n.a. & $4.59 \pm 0.14^{\mathrm{c}}$ & n.a. & n.a. & n.a. & n.a. \\
$24 \mathrm{~h}$ & n.a. & n.a. & $3.01 \pm 0.27^{\mathrm{d}}$ & n.a. & n.a. & n.a. & n.a. \\
\hline
\end{tabular}

Lower case letters a-d indicate intra-group differences $(\mathrm{p}<0.05)$, while uppercase letters A-G indicate inter-group differences $(\mathrm{p}<0.05)$

\section{Analysis of sugars in root exudates by HPIC}

Quantitative analysis of sugars in root exudates was done with HPIC using retention times of chromatographic peaks (Fig. 5), while quantitative analysis was done using the external standard method. The results of the analysis of sugars in root exudates of $F$. mandshurica (Table 2) showed that the major sugars were Fuc, Ara, Gal, Glc, Xyl, Man, Fru, and Glc-AC. The types of sugars identified varied greatly between the results for HPIC and GC-MS 
analyses, with HPIC showing much smaller amounts and fewer types of sugars than GC-MS. This occurred probably because GC-MS detected smaller amounts of sugars than HPIC. Other sugars were present in low levels in the root exudates, but the amounts were lower than the HPIC detection limit. It was also found that the type and amounts of sugars differed significantly at different collection times. The amounts and varieties of sugars tended to increase significantly as the collection time increased (0-12 h).

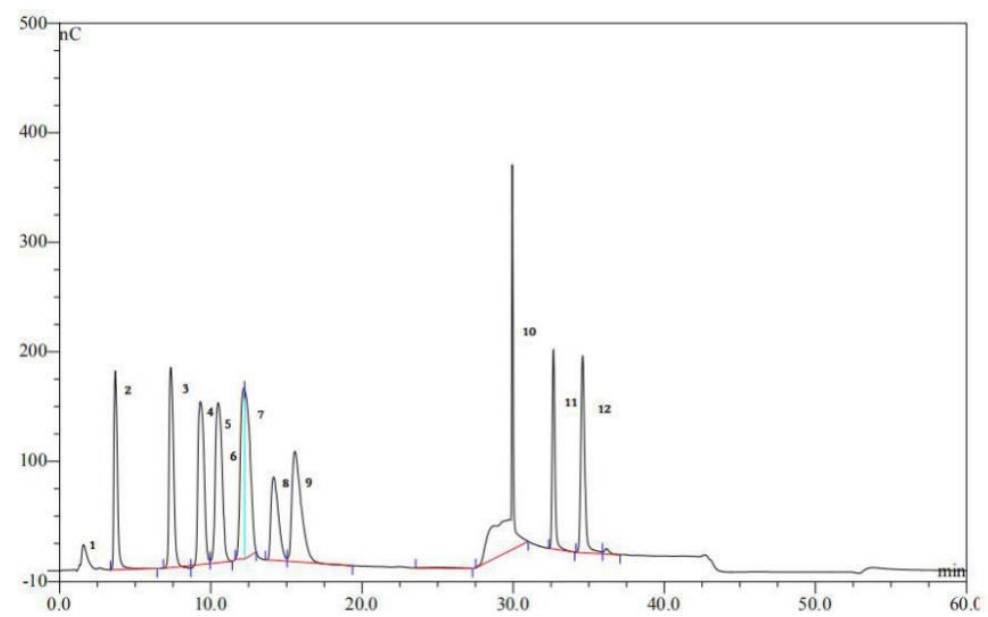

Figure 5. High performance ion chromatography (HPIC) chromatogram of sugar standards at concentration of $30 \mathrm{ug} / \mathrm{mL}$. the retention times were: peak 2, fucose (Fuc), $3.67 \mathrm{~min}$; peak 3, arabinose (Ara), 7.35 min; peak 4, galactose (Gal), 10.48 min; peak 5, glucose (Glc), 12.17 min; peak 6, mannose (Man), 12.98 min; peak 7, xylose (Xyl), 14.15 min; peak 8, fructose (Fru), 15.12 min; peak 9, ribose (Rib), 15.62 min; peak 11, galacturonic acid (Gal-AC), 32.67 min, and peak 12, glucuronic acid (Glc-AC), $34.60 \mathrm{~min}$. Peaks 1 and 10 were solvent peaks

Table 2. Sugar content of root exudates of F. mandshurica, as determined using high performance ion chromatography. (There were 4 treatments based on collection times of $6 \mathrm{~h}$, $12 \mathrm{~h}, 18 \mathrm{~h}$ and $24 \mathrm{~h}$ )

\begin{tabular}{c|c|c|c|c|c|c|c|c}
\hline \multirow{2}{*}{$\begin{array}{c}\text { Time of } \\
\text { collection }\end{array}$} & \multicolumn{7}{|c}{ Sugar content $(\mu \mathrm{g} / \mathrm{mL})$} \\
\cline { 2 - 8 } & Fuc & Ara & Gal & Glc & Xyl & Man & Fru & Glc-AC \\
\hline $6 \mathrm{~h}$ & $2.62 \pm 0.01^{\mathrm{a}, \mathrm{D}}$ & $7.14 \pm 0.24^{\mathrm{b}, \mathrm{B}}$ & $7.03 \pm 0.34^{\mathrm{b}, \mathrm{B}}$ & $20.21 \pm 0.52^{\mathrm{b}, \mathrm{A}}$ & n.a. & $4.47 \pm 0.28^{\mathrm{b}, \mathrm{C}}$ & n.a. & n.a. \\
$12 \mathrm{~h}$ & $2.59 \pm 0.02^{\mathrm{a}, \mathrm{F}}$ & $51.08 \pm 1.26^{\mathrm{a}, \mathrm{B}}$ & $9.91 \pm 0.64^{\mathrm{a}, \mathrm{D}}$ & $136.93 \pm 2.37^{\mathrm{aA}}$ & $11.27 \pm 0.62^{\mathrm{a}, \mathrm{C}}$ & $8.72 \pm 0.57^{\mathrm{a}, \mathrm{E}}$ & $12.59 \pm 0.62^{\mathrm{C}}$ & $12.05 \pm 0.71^{\mathrm{a}, \mathrm{C}}$ \\
$18 \mathrm{~h}$ & n.a. & $4.88 \pm 0.03^{\mathrm{c}, \mathrm{D}}$ & $6.28 \pm 0.11^{\mathrm{c}, \mathrm{C}}$ & $12.78 \pm 0.84^{\mathrm{c}, \mathrm{A}}$ & $10.81 \pm 0.14^{\mathrm{a}, \mathrm{B}}$ & n.a. & n.a. & $0.65 \pm 0.08^{\mathrm{b}, \mathrm{E}}$ \\
$24 \mathrm{~h}$ & n.a. & $4.33 \pm 0.03^{\mathrm{d}, \mathrm{D}}$ & $5.72 \pm 0.06^{\mathrm{d}, \mathrm{B}}$ & $4.98 \pm 0.22^{\mathrm{d}, \mathrm{C}}$ & $11.49 \pm 0.37^{\mathrm{a}, \mathrm{A}}$ & n.a. & n.a. & $0.54 \pm 0.11^{\mathrm{b}, \mathrm{E}}$ \\
\hline
\end{tabular}

Lower case letters $(a-d)$ indicate intra-group differences $(\mathrm{p}<0.05)$, while uppercase letters $(A-G)$ indicate inter-group difference $(\mathrm{p}<0.05)$

However, the amount and varieties of sugars decreased significantly after $12 \mathrm{~h}$. This occurred because $F$. mandshurica utilized the sugars from the root exudates as carbon substrates. Thus, the amount of sugar left decreased with time, and was almost exhausted at $24 \mathrm{~h}$. Interestingly, the content of xylose did not vary significantly after $12 \mathrm{~h}$, probably because the coefficient of xylose by plants and microorganisms is low (Jeffries, 1983). Therefore, the best time to collect in root exudates for the determination of sugar content 
of $F$. mandshurica was $12 \mathrm{~h}$. The content of Glc was the highest among the sugars in the root exudates, while the contents of Ara, Gal, Xyl, Man, Fru, Glc-AC were higher, with Fuc being the lowest in quantity at $12 \mathrm{~h}$, based on analysis of variance. Therefore, in the present study, HPIC had a lower limit of detection, relative to previous studies which used the anthrone and phenol-sulfuric acid colorimetric assay methods (Zhang et al., 2016; Jiang et al., 2018). Thus, the HPIC method used here can be used for the determination of low levels of sugars in root exudates.

\section{Analysis of organic acids in root exudates using HPIC}

The quantitative analysis of organic acids in root exudates was done with HPIC using external standard method, while qualitative analysis was done using the retention time of chromatographic peaks (Fig. 6). The results of the analysis of organic acids in root exudates of $F$. mandshurica (Table 3) showed that the major organic acids were propionic, valeric, lactic, succinic, tartaric, and oxalic acids.

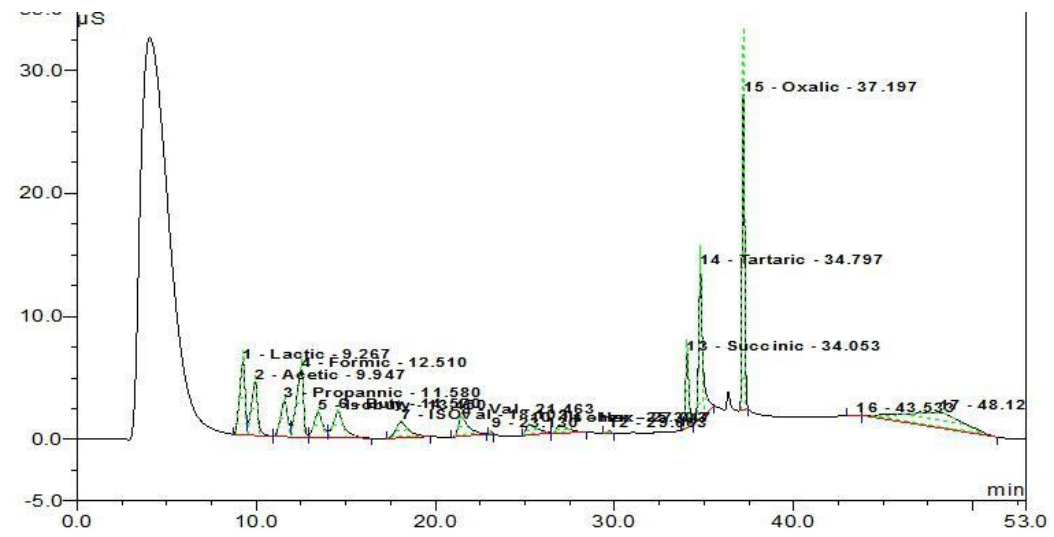

Figure 6. High performance ion chromatography (HPIC) chromatogram of organic acid standards at concentration of $40 \mu \mathrm{g} / \mathrm{mL}$. Retention times were: peak 1, lactic acid, $9.27 \mathrm{~min}$; peak 2, acetic acid, 9.95 min; peak 3, propionic acid, $11.58 \mathrm{~min}$; peak 4, formic acid, $12.51 \mathrm{~min}$; peak 5, isobutyric acid, 13.45 min; peak 6, butyrate acid, 14.57 min; peak 7, isovalerate acid, 18.10 min; peak 8, valerate acid, 21.46 min; peak 10, isohexadecanoic acid, 25.30 min; peak 11, hexadecanoic acid, 27.02 min; peak 13, succinic acid, 34.05 min; peak 14, tartaric acid, 34.80 min, and peak 15, oxalic acid, 37.20 min. Peaks 9, 12, 16, and 17 were solvent peaks

Table 3. Organic acid analysis of root exudates in F. mandshurica using high performance ion chromatography. This study had four treatments based on collection times of $6 \mathrm{~h}, 12 \mathrm{~h}$, $18 \mathrm{~h}$, and $24 \mathrm{~h}$

\begin{tabular}{c|c|c|c|c|c|c}
\hline \multirow{2}{*}{$\begin{array}{c}\text { Time of } \\
\text { collection }\end{array}$} & \multicolumn{7}{|c}{ The organic acid content $(\mu \mathrm{g} / \mathrm{mL})$} \\
\cline { 2 - 7 } & Propionic & Valeric & Lactic & Succinic & Tartaric & Oxalic \\
\hline $6 \mathrm{~h}$ & $6.37 \pm 0.22^{\mathrm{d}, \mathrm{B}}$ & n.a & n.a. & $2.69 \pm 0.19^{\mathrm{b}, \mathrm{C}}$ & $9.29 \pm 0.38^{\mathrm{d}, \mathrm{A}}$ & $1.86 \pm 0.12^{\mathrm{c}, \mathrm{D}}$ \\
$12 \mathrm{~h}$ & $13.78 \pm 0.73^{\mathrm{a}, \mathrm{B}}$ & $0.47 \pm 0.26^{\mathrm{a}, \mathrm{F}}$ & $0.84 \pm 0.19^{\mathrm{a}, \mathrm{E}}$ & $6.61 \pm 0.53^{\mathrm{a}, \mathrm{D}}$ & $22.91 \pm 0.87^{\mathrm{a}, \mathrm{A}}$ & $7.34 \pm 0.53^{\mathrm{a}, \mathrm{C}}$ \\
$18 \mathrm{~h}$ & $11.48 \pm 0.37^{\mathrm{b}, \mathrm{B}}$ & n.a & $0.13 \pm 0.08^{\mathrm{b}, \mathrm{D}}$ & $6.79 \pm 0.46^{\mathrm{a}, \mathrm{C}}$ & $23.86 \pm 0.66^{\mathrm{b}, \mathrm{A}}$ & $6.78 \pm 0.44^{\mathrm{a}, \mathrm{C}}$ \\
$24 \mathrm{~h}$ & $10.55 \pm 0.42^{\mathrm{c}, \mathrm{B}}$ & n.a & n.a. & $6.41 \pm 0.33^{\mathrm{a}, \mathrm{C}}$ & $21.61 \pm 0.59^{\mathrm{c}, \mathrm{A}}$ & $4.88 \pm 0.32^{\mathrm{b}, \mathrm{D}}$ \\
\hline
\end{tabular}

The lower case letters a-d indicate intra-group difference $(\mathrm{p}<0.05)$ and the uppercase letters of A-G indicate inter-group difference $(\mathrm{p}<0.05)$ 
These results are similar to those reported by other workers (Niu et al., 2017; Wu et al., 2018). The types of organic acids varied greatly between results from HPIC and GCMS analyses, with HPIC being less sensitive in the detection of organic acids than GCMS. This is due to the fact that GC-MS is more sensitive than HPIC, and so can detect smaller amounts of organic acids. Other organic acids were present in low levels in the root exudate, but the amounts were lower than the detection limit of HPIC. It was also found that the types and amounts of organic acids varied significantly at different collection times. The types and varieties of organic acids present tended to increase over time $(0-12 \mathrm{~h})$, with slight declines after $12 \mathrm{~h}$. Again, this trend is most likely due to the fact that $F$. mandshurica used the organic acids as carbon substrates, leading to their decline in concentration with time. Therefore, the best collection time for the determination of organic acid content of root exudates of $F$. mandshurica is $12 \mathrm{~h}$ after collection of the roots. Tartaric acid was found in the highest amount among the organic acids of root exudates, while higher levels of propionic, succinic, and oxalic acids were present at $12 \mathrm{~h}$.

\section{Conclusion}

The results obtained in this study indicate that time of collection has a strong influence on the varieties and concentrations of organic compounds in the root exudate of $F$. mandshurica obtained using water culture collection method. The collection time for qualitative analysis of sugars, amino acids, and organic acids with GC-MS can be arbitrary chosen within $24 \mathrm{~h}$, theoretically. However, the use of GC-MS in the present study has shown the presence of 219 compounds in the root exudates of $F$. mandshurica, with the highest contents at collection time of $12 \mathrm{~h}$. Over 200 compounds have been identified in the root exudates of several economic forest trees using GC-MS at collection time of $12 \mathrm{~h}$ (Sun et al., 2003). Forty compounds were found in the root exudates of Gymnorrhiza seedling using GC-MS at the collection time of $6 \mathrm{~h}$ (Liu et al., 2011). However, only 17 compounds were found in the root exudates of Rubber seedling using GC-MS, at the collection time of $6 \mathrm{~h}$ (Wang et al., 2010). In another study, over 100 compounds were identified in the root exudates of Capsicum chinense Jacquin at collection time of $120 \mathrm{~h}$ (Han et al., 2015). The use of GS-MS also resulted in the identification of 55 organic compounds in the root exudates of Fritillaria pallidiflora Schvek seedlings at collection time of $72 \mathrm{~h}$ (Wang et al., 2009). Sometimes, the results may not be accurate because of the low concentration of root exudate available at the beginning of the collection, apart from the findings that root exudates are affected by plants and microorganisms after $12 \mathrm{~h}$ (Fransson and Johansson, 2010; Shi et al., 2011).

In the present study, the optimal collection time for quantitative analysis of sugars, amino acids, and organic acids using UPLC and HPIC target analysis methods was $12 \mathrm{~h}$. The HPIC detection limit for sugar content and organic acid content was $0.1 \mu \mathrm{g} / \mathrm{mL}$. However, the HPLC detection limit of sugar content in root exudates was $3 \mu \mathrm{g} / \mathrm{mL}$ (Gao et al., 2017), while the detection limit using anthrone and phenol-sulfuric acid colorimetric assay was $10 \mu \mathrm{g} / \mathrm{mL}$ (Zhang et al., 2016). In another study, the HPLC detection limit of organic acid content in root exudates was $12.5 \mu \mathrm{g} / \mathrm{mL}$ (Gao et al., 2018). Thus, the UPLC and HPIC target analysis methods have low detection limits and relatively wider linear ranges than the current methods. Therefore, the UPLC, HPIC target analysis methods provide a good quantitative analytical method for identification and measurement root exudates. We believe that these methods should be popularized and 
widely used. Forest researchers will need to consider the collection time when gathering root exudates so as to maximize the accuracy of results from qualitative and quantitative analyses of root exudates. In addition, the water culture system used to collect root exudates in this study is free from external interferences. However, there are many microorganisms in the actual rhizosphere. These microorganisms use the exudates to carry out their own metabolic activities, thereby affecting the results of measurements. Therefore, more studies are needed on methods of determination of root exudates in rhizosphere environment, the dynamic changes in root exudates, changes in root exudates under different external influences, and mechanisms involved in plant-soil-microbe interactions mediated by root exudates.

Acknowledgements. We thank Letpub Editing (https:/www.letpub.com.cn/) for editing this manuscript. We thank the National Key R \& D Program of China (2017YFD0600605) for funding support.

Conflicts of Interests. The authors declare no conflict of interests.

\section{REFERENCES}

[1] Akiyama, K., Matsuzaki, K., Hayashi, H. (2005): Plant sesquiterpenes induce hyphal branching in arbuscular mycorrhizal fungi. - Nature 435(7043): 824-827.

[2] Bardgett, R. D., Yeates, G. W., Anderson, J. M. (2005): Patterns and determinants of soil biological diversity. - Biological Diversity \& Function in Soils 22: 100-118.

[3] Bowsher, A. W., Ali, R., Harding, S. A., Tsai, C. J., Donovan, L. A. (2015): Analysis of wild sunflower (Helianthus annuus L.) root exudates using gas chromatography-mass spectrometry. - Journal of Plant Nutrition and Soil Science 178(5): 776-786.

[4] Carvalhais, L. C., Dennis, P. G., Fedoseyenko, D., Borriss, R., vonWiren, N. (2011): Root exudates of sugars, amino acids, and organic acids by maize as affected by nitrogen, phosphorus, potassium, and iron deficiency. - Journal of Plant Nutrition and Soil Science 174(1): 3-11.

[5] Chang, E. H., Zhang, S. F., Wang, Z. Q., Wang, X. M., Zhang, J. H. (2008): Effect of Nitrogen and Phosphorus on the Amino Acids in Root Exudates and Grains of Rice During Grain Filling. - Acta Agronomica Sinica 34(4): 612-618.

[6] Dietrich, S., Floegel, A., Troll, M., Kühn, T., Rathmann, W., Peters, A., Sookthai, D., von Bergen, M., Kaaks, R., Adamski, J., Prehn, C., Boeing, H., Schulze, M. B., Illig, T., Pischon, T., Knüppel, S., Wang-Sattler, R., Drogan, D. (2016): Random Survival Forest in practice: a method for modelling complex metabolomics data in time to event analysis. International Journal of Epidemiology 45(5): 1406-1420.

[7] Dijkstra, F. A., Cheng, W. (2007): Moisture modulates rhizosphere effects on C decomposition in two different soil types. - Soil Biology \& Biochemistry 39(9): 22642274.

[8] Dinkelaker, B., Römheld, V., Marschner, H. (2010): Citric acid excretion and precipitation of calcium citrate in the rhizosphere of white lupin (Lupinus albus L.). - Plant, Cell \& Environment 12(3): 285-292.

[9] Dong, Y., Dong, K., Tang, L., Zheng, Y., Li, X. R., Hu, G. B., Liu, Y. M. (2015): Relationship of free amino acids in root exudates with wilt disease (FUSARIUM OXYSPORUM) of faba bean. - Acta pedologica sinica 52(4): 919-925.

[10] Fransson, P. M., Johansson, E. M. (2010): Elevated CO and nitrogen influence exudates of soluble organic compounds by ectomycorrhizal root systems. - FEMS Microbiology Ecology 71(2): 186-196. 
[11] Gao, Q., Han, Z. T. (2017): Determination of soluble sugars in forest biomass raw materials by high performance liquid chromatography-differential refractive index detector. Chinese Journal of Analysis Laboratory 36(12): 1406-1410.

[12] Gao, Y. Y., Peng, Z. F., Yang, C., Chang, M. Y., Zhu, M. L. (2018): Determination of the Effect of Organic Acids in Ricinus Communis L. Roots under Copper Stress by HPLC. Guangdong Chemical Industry 45(21): 10-14.

[13] García, J. A. L., Barbas, C., Probanza, A., Barrientos, M. L., Gutierrez Mañero, F. J. (2010): Low molecular weight organic acids and fatty acids in root exudates of two Lupinus cultivars at flowering and fruiting stages. - Phytochemical Analysis Pca 12(5): 305-311.

[14] Gargallogarriga, A., Wright, S. J., Sardans, J., Pérez-Trujillo, M., Oravec, M., Večeřová, K., Urban, O., Fernández-Martínez, M., Parella, T., Peñuelas, J. (2017): Long-term fertilization determines different metabolomic profiles and responses in saplings of three rainforest tree species with different adult canopy position. - Plos One 12(5): 177030.

[15] Han, X., Yang, Y., Sun, J. H., Liu, Z. H., Niu, Y., Cao, Z. M. (2015): Identification of chemical components of root exudates of sand-cultured capsicum Chinese Jacquin. Chinese Journal of Tropical Agricultural 35(12): 73-79.

[16] Huang, C., Webb, M. J., Graham, R. D. (1996): Pot size affects expression of Mn efficiency in barley. - Plant and Soil 178(2): 205.

[17] Jeffries, T. W. (1983): Utilization of xylose by bacteria, yeasts, and fungi. - Advances in Biochemical Engineering / Biotechnology 27(27): 1-32.

[18] Jiang, Z., Xiao, X. J., Zhang, Z. L., Qiao, M. F., He, W., Liu, Q., Yin, H. J. (2018): Effects of night-time warming on the rates and main chemical components of root exudates produced by Picea asperata seedlings in subalpine coniferous forests. - Acta ecologica sinica 38(9): 308-309.

[19] Kajos, M. K., Rantala, P., Hill, M., Hellén, H., Aalto, J., Patokoski, J., Taipale, R., Hoerger, C. C., Reimann, S., Ruuskanen, T. M., Rinne, J., Petäjä, T. (2015): Ambient measurements of aromatic and oxidized VOCs by PTR-MS and GC-MS: intercomparison between four instruments in a boreal forest in Finland. - Atmospheric Measurement Techniques 8(4): 3753-3802.

[20] Kerdchoechuen, O. (2005): Methane emission in four rice varieties as related to sugars and organic acids of roots and root exudates and biomass yield. - Agriculture Ecosystems \& Environment 108(2): 155-163.

[21] Kuo, Y. H., Lambein, F., Ikegami, F., Van Parijs, R. (1982): Isoxazolin-5-ones and Amino Acids in Root Exudates of Pea and Sweet Pea Seedlings. - Plant Physiology 70(5): 12831289.

[22] Li, L., Li, S. M., Sun, J. H., Zhou, L. L., Bao, X. G., Zhang, H. G., Zhang, F. S. (2007): Diversity enhances agricultural productivity via rhizosphere phosphorus facilitation on phosphorus-deficient soils. - Proceedings of the National Academy of Sciences of the United States of America 104(27): 11192-11196.

[23] Li, J., Jiang, X. M., Yin, H. J., Yin, C. Y., Wei, Y. H., Liu, Q. (2014): Root exudates and soil microbes in three Picea asperata plantations with different stand ages. - Ying Yong Sheng Tai Xue Bao 25(2): 325-332.

[24] Liu, X. Y., Chen, X., Wu, L., Chen, M., Zhou, K. B. (2016): GC-MS Analysis of Root Exudates of Gymnorrhiza Seedings. - Chinese Journal of Tropical Crops 37(4): 835-843.

[25] Luo, Q., Sun, L. N., Hu, X. M. (2014): The variation of root exudates from the hyperaccumulator Sedum alfredii under cadmium stress: metabonomics analysis. - Plos One 9(12): 115581.

[26] Malandrino, M., Abollino, O., Buoso, S., Giacomino, A., La Gioia, C., Mentasti, E. (2011): Accumulation of heavy metals from contaminated soil to plants and evaluation of soil remediation by vermiculite. - Chemosphere $82(2)$ : 169-178.

[27] Maqsood, M. A., Hussain, S., Aziz, T., Ashraf, M. (2011): Wheat-Exuded Organic Acids Influence Zinc Release from Calcareous Soils. - Pedosphere 21(5): 657-665. 
[28] Materechera, S. A., Dexter, A. R., Alston, A. M. (1992): Formation of aggregates by plant roots in homogenised soils. - Plant \& Soil 142(1): 69-79.

[29] Mei, L., Wang, Z., Han, Y., Gu, J., Wang, X., Cheng, Y., Zhang, X. J. (2006): Distribution patterns of Fraxinus mandshurica root biomass, specific root length and root length density. - Chinese Journal of Applied Ecology 17(1): 1-4.

[30] Niu, F. H., Li, Z. H., Chen, S. X. (2017): Effect of Phosphorus Levels on Organic Acids in Eucalyptus duhhii Root Exudates. - Eucalypts Science \& Technology 34(1): 1-8.

[31] Oades, J. M. (2010): Mucilages at the root surface. - European Journal of Soil Science 29(1): 1-16.

[32] Pan, S. W., Yuan, X., Liu, C., Li, Y. L., Yang, T., Tang, H. Y., Huang, F. Y. (2016): Effects of Pyrene on Low Molecule Weight Organic Compounds in the Root Exudates of Five Species of Festuca. - Environmental Science 37(6): 2368-2375.

[33] Paynel, F., Murray, P. J., Cliquet, J. B. (2001): Root exudates: A pathway for short-term N transfer from clover and ryegrass. - Plant \& Soil 229(2): 235-243.

[34] Peters, N. K., Frost, J. W., Long, S. R. (1986): A plant flavone, luteolin, induces expression of Rhizobium meliloti nodulation genes. - Science 233(4767): 977-980.

[35] Phillips, R. P., Fahey, T. J. (2006): Tree Species and Mycorrhizal Associations Influence the Magnitude of Rhizosphere Effects. - Ecology 87(5): 1302-1313.

[36] Phillips, R. P., Bernhardt, E. S., Schlesinger, W. H. (2009): Elevated $\mathrm{CO}_{2}$ increases root exudates from loblolly pine (Pinus taeda) seedlings as an N-mediated response. - Tree Physiology 29(12): 1513-1523.

[37] Ren, J., Xu, C. Y., Wei, Y. B., Lin, Y. M., Duan, Y. H. (2010): Seasonal dynamics and influence factor of root respiration of Fraxinus mandushurica in the Changbai Mountain. Scientia Silvae Sinicae 46(5): 77-83.

[38] Rissanen, T., Hyötyläinen, T., Kallio, M., Kronholm, J., Kulmala, M., Riekkola, M. L. (2006): Characterization of organic compounds in aerosol particles from a coniferous forest by GC-MS. - Chemosphere 64(7): 1185-1195.

[39] Sandnes, A., Eldhuset, T. D., Wollebaek, G. (2005): Organic acids in root exudates and soil solution of Norway spruce and silver birch. - Soil Biology \& Biochemistry 37(2): 259269.

[40] Selvakumar, G., Panneerselvam, P. (2012): Bacterial Mediated Alleviation of Abiotic Stress in Crops. Bacteria in Agrobiology: Stress Management. - Springer Berlin Heidelberg 34(2): 205-224.

[41] Shi, S., Condron, L., Larsen, S., Richardson, A. E., Jones, E. E., Jiao, J., O'Callaghan, M., Stewart, A. (2011): In situ sampling of low molecular weight organic anions from rhizosphere of radiata pine (Pinus radiata) grown in a rhizotron system. - Environmental \& Experimental Botany 70(2): 131-142.

[42] Singh, G., Mukerji, K. G. (2006): Root Exudates as Determinant of Rhizospheric Microbial Biodiversity. - Soil Biology 7: 39-53.

[43] Sun, H. Y., Wang, Y. Z., Yang, L. (2003): Analysis of the major components of root exudates released from several economic forest tree using GC-MS. - Journal of Forestry Research 14(2): 127-129.

[44] Suzuki, K., OkazakiI, K., Tawaraya, K., Osaki, M., Shinano, T. (2009): Gas chromatography-mass spectrometry associated global analysis of rice root exudates under aseptical conditions. - Soil Science \& Plant Nutrition 55(4): 505-513.

[45] Venkatasubbarao, G., NoriharuAe, T. (1997): Genotypic variation in iron-, and aluminumphosphate solubilizing activity of pigeonpea root exudates under $\mathrm{P}$ deficient conditions. Soil Science \& Plant Nutrition 43(2): 295-305.

[46] Wang, Y., Kaisar, S., Li, J., Zhu, G. Q., Song, T. S., Liu, L. (2009): Analysis of Components in Root Exudates of Fritillaria pallidiflora Schvek Seedlings at Different Ages by Gas Chromatography-mass Spectrometry. - Acta Botanica Boreali-Occidentalia Sinica 29(2): 384-389. 
[47] Wang, W. B., Wu, X. P., Yin, Y. L., Guo, H. C., Luo, X. H. (2010): GC-MS Analysis of Rubber Seedling Root Exudates with Nutrient Solution Cultivation. - Chinese Journal of Tropical Crops 31(12): 2281-2286.

[48] Wang, J. X., Zhan, F. D., Li, Y., Zu, Y. Q., Qin, L., He, Y. M. (2016): Effects of Arabisalpina L. var. parviflora Franch and Zea mays L. intercropping system on rootexudated organic acids under lead stress. - Chinese Journal of Eco-Agriculture 24(3): 365372.

[49] Wu, C. C., Liu, J., Zhang, X. D. (2018): Determination of organic acids in the root exudates of Cr-hyperaccumulator Leersia hexandra Swartz using high performance liquid chromatography. - Chinese Journal of Chromatography 36(2): 167-172.

[50] Xiao, J. X., Zheng, Y., Tang, L., Dong, Y. (2015): Effect of Wheat and Faba Bean Intercropping on Sugar and Amino Acid Exuded by Roots. - Ecology and Environmental Sciences 24(11): 1825-1830.

[51] Yin, H., Li, Y., Xiao, J., Xu, Z., Cheng, X., Liu, Q. (2013): Enhanced root exudates stimulates soil nitrogen transformations in a subalpine coniferous forest under experimental warming. - Global Change Biology 19(7): 2158-2167.

[52] Young, R. F., Coy, D. L., Fedorak, P. M. (2010): Evaluating MTBSTFA derivatization reagents for measuring naphthenic acids by gas chromatography-mass spectrometry. Analytical Methods 2(6): 765-770.

[53] Zhang, X. Z., Li, T. X., Wang, Y. D. (2007): Relationship between growth environment and root exudates of plants: A review. - Chinese Journal of Soil Science 38(4): 785-789.

[54] Zhang, A. H., An, N. B., Lei, F. J., Ma, W. L., Chi, K., Zhang, L. X. (2016): Chemotaxis response of Erwinia carotovora on sugars and amino acids of root exudates of Panax ginseng. - China Journal of Chinese Materia Medica 41(21): 3937-3941.

[55] Zhen, W., Wang, X., Cao, K., Jin, Z. J. (2004): Study on determination and allelopathy of amino acids in strawberry root exudates and decomposing products. - Journal of Agricultural University of Hebei 27(2): 76-80. 